\title{
Hematopoietic Microenvironment
}

\author{
Origin, Lineage, and Transplantability of the Stromal Cells in Long-term \\ Bone Marrow Cultures from Chimeric Mice
}

\author{
Steve Perkins and Roger A. Fleischman \\ Department of Internal Medicine, Division of Hematology/Oncology, University of Texas Health Science Center, Dallas, Texas 75235
}

\begin{abstract}
Studies of bone marrow transplant patients have suggested that the stromal cells of the in vitro hematopoietic microenvironment are transplantable into conditioned recipients. Moreover, in patients with myeloproliferative disorders, all of the stromal cells, which include presumptive endothelial cells, appear to be derived from hematopoietic precursors. To confirm these findings, we have constructed two chimeric mouse models: (a) traditional radiation chimeras, and (b) fetal chimeras, produced by placental injection of bone marrow into genetically anemic $W^{x} / W^{v}$ fetuses, a technique that essentially precludes engraftment of nonhematopoietic cells. Using two-color indirect immunofluorescence, the stromal cells in long-term bone marrow culture derived from these chimeras were analyzed for donor or host origin by strain-specific $\mathbf{H}-2$ antigens, and for cell lineage by a variety of other specific markers. $75-95 \%$ of the stromal cells were shown to be hematopoietic cells of the monocyte-macrophage lineage, based upon donor origin, phagocytosis, and expression of specific hematopoietic surface antigens. The remaining 5-25\% of the stromal cells were exclusively host in origin. Apart from occasional fat cells, these cells uniformly expressed collagen type IV, laminin, and a surface antigen associated with endothelial cells. Since these endothelial-like cells are not transplantable into radiation or fetal chimeras, they are not derived from hematopoietic stem cells. The contrast between our findings and human studies suggests either unexpected species differences in the origin of stromal lineages or limitations in the previous methodology used to detect nonhematopoietic stromal cells.
\end{abstract}

\section{Introduction}

The long-term bone marrow culture system (LTBC) ${ }^{1}$ has proved to be a useful model for the characterization of the hematopoietic microenvironment in vitro $(1,2)$. Indeed, the

Portions of this work were presented in 1987 at the UCLA Symposium on Tumor Progression and Metastasis. This portion appeared in abstract form in 1987. (J. Cell. Biochem. Suppl. 11D:111).

Address all correspondence to Dr. Fleischman, Department of Internal Medicine, Division of Hematology/Oncology, University of Texas Health Science Center, Dallas, TX 75235.

Received for publication 27 July 1987 and in revised form 22 October 1987.

1. Abbreviations used in this paper: $\mathrm{CFU}-\mathrm{GM}, \mathrm{CFU}-g r a n u l o c y t e-m a c-$ rophage; CFU-S, CFU-spleen; GPI, D-glucose-6-phosphate-ketolisomerase; LTBC, long-term bone marrow culture.

J. Clin. Invest.

(C) The American Society for Clinical Investigation, Inc. 0021-9738/88/04/1072/09 \$2.00

Volume 81, April 1988, 1072-1080 maintenance of hematopoiesis in LTBC is critically dependent upon a population of "stromal" cells and matrix, defined by their adherence to the surface of the culture vessel.

Despite extensive investigation, the precise lineage and origin of the cells comprising the in vitro hematopoietic microenvironment is uncertain. For example, some workers have reported that the adherent cells in LTBC are predominantly fibroblasts and that endothelial cells are undetectable (3). In contrast, others have found substantial numbers of endothelial-like cells $(4,5)$. Similarly, some but not all studies have concluded that the stromal cells are transplantable after either radiation- or drug-conditioning, and have further suggested that the stromal cells are derived from the hematopoietic stem cell (5-9).

To unequivocally define the origin of cells in the microenvironment, we have exploited a novel chimera model that utilizes stem cell-deficient $W^{x} / W^{v}$ mice, which accept bone marrow without the necessity for radiation or cytotoxic conditioning. These unique chimeras are produced by intraplacental inoculation of bone marrow during fetal life, at a stage in development when there is no bone marrow and the liver is the site of hematopoiesis $(10,11)$. Not only does this technique avoid radiation and resultant stromal injury, it also essentially eliminates the possibility of stromal precursor transplantation reported in studies of radiation chimeras (12).

Using LTBC prepared from these chimeric mice, as well as traditional radiation chimeras, we have carried out an in situ analysis of the individual cells constituting the stromal population. Donor and host cells were distinguished by surface immunofluorescence staining for strain-specific histocompatibility antigens and further identified by lineage-specific cytoplasmic markers. Exploiting this approach, we have been able to characterize virtually all the cells constituting the in vitro stroma.

\section{Methods}

Mice. All mice were obtained from Jackson Laboratory (Bar Harbor, ME). For construction of fetal chimeras, the severely anemic $W^{x} / W^{v}$ recipients were derived from matings of $\mathrm{C} 57 \mathrm{BL} / 6-W^{v}$ heterozygous females $\left(H-2 K^{b / b}\right)$, and $\mathrm{C} 3 \mathrm{H} / \mathrm{He}-W^{x}$ heterozygous males $\left(H-2 K^{k / h}\right)$. For radiation chimeras, 2-4 mo old [C57BL/6 $\times$ AKR/J] F1 recipients $\left(H-2 K^{b / h}\right)$ were used. Donor animals for both the fetal and radiation chimeras were 8-12 wk old AKR females $\left(H-2 K^{k / h}\right) . H-2 K^{b}$ was therefore unique to the recipients.

Preparation and characterization of chimeric mice. Fetal chimeras were constructed by placental injection as previously described $(10$, 11). Briefly, a marrow cell suspension was prepared by flushing donor femurs with PBS and filtering them through a sterilized filter with $\mathbf{4 0}$ $\mu \mathrm{m}$ pore size (Nitex HC3-41; Tetko, Elmsford, NY). On day 11 of gestation, with the pregnant female under Nembutal anesthesia, the fetuses were exposed through a dorsolateral incision and $\sim 10^{6}$ donor cells were injected with a micropipette into each placenta. The incision was then sutured closed. $25 \%$ of the fetuses would be expected to be $W^{x} / W^{v}$ anemics in these matings. 
Radiation chimeras were constructed by injection of $10^{7}$ donor marrow cells, prepared as described above, into the tail vein of recipients irradiated with $9.5 \mathrm{~Gy}$, at a rate of $0.85 \mathrm{~Gy} / \mathrm{min}$ from a cobalt source, immediately before transplantation.

The degree of erythroid engraftment was assessed at regular intervals by cellulose acetate electrophoretic separation of strain-specific variants of GPI (D-glucose-6-phosphate ketol-isomerase, EC 5.3.1.9) (Gpi-1 locus) according to the method described by Eldridge and Dewey (13). Similarly, at the time of explantation, the extent of donor reconstitution in hematopoietic tissues and organs was determined by GPI analysis.

Hematopoietic progenitor cell assays. Granulocyte-macrophage colony-forming cells (CFU-GM) were assayed according to published methods, using endotoxin-conditioned mouse serum as a stimulator (14). 11-d spleen colony-forming units (CFU-S) were assayed by the method of Till and McCulloch (15).

Long-term bone marrow cultures. The method of Dexter et al. (1) was used with the following modifications. Chimeric mice were killed by cervical dislocation and the femurs and tibiae removed by sterile dissection. Marrow was flushed from the bones with culture medium and clumps disrupted by gently pipetting through a Pasteur pipette. The cells were suspended at a final concentration of $10^{6} / \mathrm{ml}$ in Iscove's modified DME (Sigma Chemical Co., St. Louis, MO) supplemented with $20 \%$ horse serum (GIBCO, Grand Island, NY), $50 \mathrm{U} / \mathrm{ml}$ penicillin, $50 \mu \mathrm{g} / \mathrm{ml}$ streptomycin, and $10^{-6} \mathrm{M}$ hydrocortisone hemisuccinate (Sigma Chemical Co.). Cultures were incubated in a humidified atmosphere with $5 \% \mathrm{CO}_{2}$ at $33^{\circ} \mathrm{C}$ in $35 \mathrm{~mm}$ suspension dishes (Miles Scientific Div., Miles Laboratories Inc., Naperville, IL), each containing a sterilized 22-mm-square glass coverslip (American Scientific Products Div., American Hospital Supply Corp., McGaw Park, IL), and $1.5 \mathrm{ml}$ of the cell suspension.

At weekly intervals all the medium and nonadherent cells were removed and replaced with fresh medium. Control experiments to assess the competence of adherent layers formed on glass coverslips demonstrated the maintenance of CFU-GM and CFU-S production in vitro for at least $8 \mathrm{wk}$.

3-4 d before immunofluorescence staining, $1,000 \mathrm{U} / \mathrm{ml}$ of $\alpha \beta$-interferon (Lee Biomolecular Research Laboratories, Inc., San Diego, CA) was added to the cultures to enhance the expression of $H-2 K$ surface antigens (16). At the time of immunofluorescence analysis for the strain-specific histocompatibility antigens, some of the adherent layers were resuspended by trypsinization and analyzed by GPI electrophoresis as an independent measure of the proportion of donor- and host-derived cells.

Antisera. All antibodies were diluted in PBS with 1\% BSA and $0.1 \%$ sodium azide. Washing solution was PBS with $0.5 \mathrm{mM} \mathrm{MgSO}_{4}$ and 1 $\mathrm{mM} \mathrm{CaCl}{ }_{2}$.

The mouse IgM anti-H-2K $\mathrm{MAb}$ was obtained from Bionetics Laboratory Products Div., Litton Bionetics Inc., Charleston, SC, and used at a dilution of 1:50. FITC-conjugated goat anti-mouse IgM (Fab fragment, affinity-purified) was obtained from Cappel Laboratories, Malvern, PA, and was used at a dilution of 1:50 as the second step reagent.

Rat MAbs to the hematopoietic surface antigens T200 (Ly-5) (17) and Mac-1 (18) were obtained from Hybritech Inc., San Diego, CA, and were used at a dilution of 1:50. F4/80, a rat MAb specific for mouse macrophages (19), was kindly provided as a gift by Dr. R. Steinman, Rockefeller University. FITC-conjugated goat anti-rat IgG was obtained from Cappel Laboratories and was used at a dilution of $1: 100$.

Sheep anti-human collagen IV antiserum, a gift of Dr. F. Grinnell, Southwestern Medical School, was the extensively characterized preparation described by Dr. S. Katz (20), and was used at a dilution of 1:700. Tetramethyl rhodamine isothiocyanate-conjugated rabbit anti-sheep IgG antiserum was purchased from Jackson Immunoresearch Laboratories, Inc., Avondale, PA, and was used at a dilution of $1: 15$.
FITC-conjugated rabbit anti-laminin antiserum was purchased from Polysciences, Inc., Warrington, PA, and was used at a dilution of 1:30. Rabbit anti-human Factor VIII antiserum was obtained from Dako, Denmark, and was used at a dilution of 1:15. Its activity was confirmed on mouse megakaryocytes and cultured human endothelial cells. FITC-conjugated goat anti-rabbit IgG (Cappel Laboratories) was used as the second step. FITC-conjugated goat anti-human Factor VIII (dilution 1:20) was obtained from Atlantic Antibodies, Scarborough, ME.

Goat anti-collagens I and III antisera were obtained from Southern Biotechnology Associates, Inc., Birmingham, AL, and FITC-conjugated rabbit anti-goat IgG from Cappel Laboratories.

Rabbit anti-mouse fibronectin was obtained from Accurate Chemical and Scientific Corp., Westbury, NY. Rabbit anti-chicken actin was purchased from Polysciences, Inc.

Rat MAbs, MECA-10 and MECA-325, raised against antigenic determinants on endothelial cells, were kindly provided by Dr. E. C. Butcher (21). $48 \mathrm{~h}$ before staining with the MECA antibodies, 100 $\mathrm{U} / \mathrm{ml}$ of $\gamma$-interferon (provided by Dr. M. Ziff, Southwestern Medical School) was added to each culture.

Collagen types I and IV (Collaborative Research, Bedford, MA), were used in blocking studies of the anti-collagen IV antiserum at concentrations of 1.7 and $0.8 \mathrm{nmol}$, respectively.

Surface immunofluorescence. At 3-4 wk and 5-6 wk in culture, the adherent cells were analyzed by immunofluorescence. All staining was done at $4^{\circ} \mathrm{C}$. After cooling for $1 \mathrm{~h}$, all nonadherent cells and medium were removed, and three 5-min washes were performed in $13-\mathrm{mm}$ weigh-boats filled with washing solution. The coverslips were then placed, culture-surface down, on $60 \mu \mathrm{l}$ of antibody that had been deposited on glass slides. These were then placed in a humidified chamber for $20 \mathrm{~min}$. Next, the coverslips were floated off the slides into the washing solution and washed again as above. Second step staining was performed as it was for the first step and was followed by three more washes. The cells were then fixed in $1 \%$ paraformaldehyde (Eastman Kodak Co., Rochester, NY) in PBS for 20 min before further staining or mounting. For histochemistry, fixation was in $0.5 \%$ paraformaldehyde. The coverslips were then mounted in a mounting buffer containing three parts glycerol, one part PBS, $0.1 \%$ sodium azide, and $25 \mathrm{~g} /$ /iter diazabicyclooctane (Aldrich Chemical Co., Milwaukee, WI). In the analysis of adherent layers from chimeric mice, at least three layers from each animal were used.

Cytoplasmic immunofluorescence. The cells were fixed in citratebuffered acetone for $30 \mathrm{~s}$ and then air-dried for $30 \mathrm{~min}$ at room temperature. After one more wash, staining and mounting were performed as above, but without poststaining fixation.

Phagocytosis. 24-48 h before staining, $3 \mu \mathrm{l}$ of $1.1 \mu \mathrm{m}$ latex particles (Seragen Diagnostics, Inc., Indianapolis, IN) were added to each culture dish to detect phagocytic activity. In parallel experiments, the identical procedure was carried out using $0.9 \mu \mathrm{m}$ fluorescent covaspheres (Covalent Technology Co., Ann Arbor, MI). Although most of the phagocytic cells contained numerous particles, cells containing more than five particles were scored as phagocytic.

Cytochemistry. Alkaline phosphatase activity was detected using naphthol AS-MX phosphate and fast violet $B$, and acid phosphatase was detected using naphthol AS-BI phosphoric acid and fast garnet GBC salt (Sigma Chemical Co.). Specific esterase was detected using naphthol AS-D chloroacetate and fast corinth $\mathrm{V}$ salt, while nonspecific esterase was detected using alpha-naphthyl acetate and fast blue RR salt (Sigma Chemical Co.).

For staining of fat cells, the mounted coverslips were floated off the slides, washed in PBS, and allowed to dry. They were then stained with Sudan black B in alcoholic phenol phosphate buffer for $1 \mathrm{~h}$ at room temperature, rinsed in $70 \%$ ethanol followed by tap water, and air dried (22).

To analyze the same cells by both immunofluorescence and cytochemical staining, numerous fields were first examined for surface fluorescence while noting the horizontal and vertical axes on the mi- 
croscope stage. Photographs of these fields were taken, and after cytochemical staining the same fields were located and reexamined.

Microscopy and photography. All coverslips were examined with a fluorescent microscope (Carl Zeiss, Inc., Thornwood, NY) and photographs were taken with a camera (Carl Zeiss, Inc.,) using Kodak Tri-X film (Eastman Kodak Co., Rochester, NY). Sequential fields were examined and all the cells were counted and designated as donor or recipient in origin based on the absence or presence, respectively, of surface fluorescence with the anti- $H-2 K^{b}$ stain.

\section{Results}

Expression of strain-specific histocompatibility antigens distinguishes the donor or host origin of adherent cells in $L T B C$. As shown in Table $\mathrm{I}$, the MAb directed against the $H-2 K^{b}$ determinant stained $>99 \%$ of the adherent cells that were derived from host strain mice $\left(H-2 K^{k / b}\right)$. None of the cells from donor strain mice $\left(H-2 K^{k / k}\right)$ were stained. Thus, in the analysis of chimeric mice, positive staining with this antibody unequivocally identified cells as host in origin, while negative staining accurately identified the donor cells.

Adherent cells in LTBC derived from chimeric mice are predominantly donor in origin. At the time of explantation, the extent of bone marrow reconstitution with donor cells was assessed by analysis of the blood and bone marrow for strainspecific variants of GPI. As shown in Table II, in fetal and radiation chimeras explanted at $>10$ mo of age, the red cells, white cells, and bone marrow cells were at least $95 \%$ donor in origin. Hematopoiesis in two additional fetal chimeras, analyzed at 2 and 4 mo of age, was predominantly, but not yet completely, donor derived.

$3 \mathrm{wk}$ after explantation, the adherent cells in the subconfluent LTBC were typed for donor or host origin by immunofluorescence staining as described above. As shown in Table II, $\sim 90 \%$ of the cells from completely reconstituted chimeras were donor in origin. The remaining $10 \%$ of the adherent cell population from these chimeras, on the other hand, expressed the host strain-specific antigen. In the fetal chimera studied at

Table I. Immunofluorescence Staining of Donor and Host Strain Control Adherent Cells with the Host Strainspecific Anti-H-2K MAb

\begin{tabular}{lcc}
\hline \multicolumn{2}{c}{ Adherent layers } & \\
\cline { 1 - 2 } Mouse strain & $H-2 K$ genotype & \% Positive (No. of cells counted) \\
F1 (host) & $k / b$ & $99.9(850)$ \\
& & $99.1(1068)$ \\
& & $99.6(1016)$ \\
& & $99.8(1039)$ \\
AKR (donor) & $k / k$ & $0(600)$ \\
& & $0(1113)$ \\
& & $0(1023)$ \\
& & $0(1006)$
\end{tabular}

Sensitivity: $99.6 \%$

Specificity: $100 \%$

Accuracy: $99.7 \%$

Two mice of each strain were used. Each count is from a different adherent layer.
Table II. Percentage of Donor-derived Cells in Hematopoietic Tissues and Adherent Layers of Chimeric Mice Determined by GPI Electrophoresis and H-2 Immunofluorescence

\begin{tabular}{|c|c|c|c|c|c|c|}
\hline \multirow[b]{3}{*}{ Chimera } & \multirow[b]{3}{*}{ Age } & \multirow{2}{*}{\multicolumn{3}{|c|}{ Tissues }} & \multicolumn{2}{|c|}{ Adherent layers } \\
\hline & & & & & \multirow{2}{*}{$\begin{array}{c}H-2 \\
\text { (cells counted) }\end{array}$} & \multirow{2}{*}{$\begin{array}{c}\text { GPI } \\
\text { (age of culture) }\end{array}$} \\
\hline & & rbc & wbc & bm & & \\
\hline & mo & & & & & \\
\hline \multirow[t]{2}{*}{ Radiation } & 10 & 99 & 95 & 99 & $88(1,442)$ & 75 (3 wk) \\
\hline & & & & & & 80 (5 wk) \\
\hline Radiation & 11 & 100 & 100 & 100 & $88(980)$ & 90 (3 wk) \\
\hline Radiation & 12 & 100 & 100 & 100 & $90(1,574)$ & 95 (3 wk) \\
\hline Radiation & 13 & 100 & 100 & 100 & ND & 85 (3 wk) \\
\hline \multirow[t]{3}{*}{ Fetal } & 24 & 99 & 95 & 100 & $92(472)$ & 90 (3 wk) \\
\hline & & & & & & 80 (5 wk) \\
\hline & & & & & & 90 (8 wk) \\
\hline Fetal & 17 & 100 & 100 & 100 & ND & 80 (3 wk) \\
\hline \multirow[t]{2}{*}{ Fetal } & 4 & 80 & ND & ND & $9(673)$ & 10 (3 wk) \\
\hline & & & & & & 5 (5 wk) \\
\hline \multirow[t]{2}{*}{ Fetal } & 2 & 90 & 40 & 60 & ND & 30 (3 wk) \\
\hline & & & & & & 20 (8 wk) \\
\hline
\end{tabular}

ND, not done; rbc, red blood cells; wbc, white blood cells; bm, bone marrow.

4 mo of age, the incomplete donor replacement evident at the time of explantation was even more pronounced in the corresponding LTBC, as demonstrated by the immunofluorescence analysis.

In addition to these immunofluorescence studies, parallel cultures were analyzed for the proportions of donor- and hostderived electrophoretic variants of GPI. As shown in Table II, the percentage of donor-derived cells, determined by GPI electrophoresis, correlated closely with the results obtained by immunofluorescence. In cultures examined at 5-6 wk, the presence of crowding and overlapping cells made accurate counting of cells more difficult. However, the GPI analyses demonstrated that the percentage of donor-derived cells remained relatively constant, ranging from 80 to $90 \%$ in the completely reconstituted chimeras.

The donor-derived adherent cells in LTBC are hematopoietic cells of the monocyte-macrophage lineage. The donor-derived cells were round or elongated with small nuclei. These cells were positive for acid phosphatase and nonspecific esterase, findings consistent with the monocyte-macrophage cell lineage (Table III). In addition, they were uniformly positive with the macrophage-specific MAb F4/80, as well as with MAbs directed against the Mac-1 and T200 antigens found exclusively on hematopoietic cells $(17,18)$. In contrast, the donor-derived cells did not express a variety of cytoplasmic antigens normally associated with nonhematopoietic cells, such as collagens I, III and IV, laminin, and fibronectin.

As expected for cells of the monocyte-macrophage lineage, donor-derived cells also exhibited marked phagocytic activity for fluorescent covaspheres or latex particles. However, in all chimeras studied, $5-30 \%$ of the donor-derived cells were negative in these assays, despite 48-72-h incubation periods with these markers. Nevertheless, nonphagocytic donor-derived cells were morphologically similar to the phagocytic cells and 
Table III. Presence of Antigenic and Histochemical Markers on the Adherent Cells in LTBC*

\begin{tabular}{|c|c|c|c|c|}
\hline & \multicolumn{2}{|c|}{ Donor } & \multicolumn{2}{|c|}{ Host } \\
\hline & Phagocytic & Nonphagocytic & Collagen IV & Other \\
\hline \multicolumn{5}{|l|}{$\begin{array}{r}\text { Cytoplasmic } \\
\text { antigens }\end{array}$} \\
\hline Collagen I & - & - & - & - \\
\hline Collagen III & - & - & - & - \\
\hline Laminin & - & - & + & - \\
\hline Fibronectin & - & - & + & - \\
\hline Actin & + & + & + & + \\
\hline Factor VIII ${ }^{\ddagger}$ & - & - & - & - \\
\hline \multicolumn{5}{|l|}{ Surface antigens $\mathbf{s}^{\S}$} \\
\hline T200 (Ly5) & + & + & - & ND \\
\hline $\mathrm{F} 4 / 80$ & + & + & - & ND \\
\hline Mac-1 & + & + & - & ND \\
\hline MECA-10 & - & - & + & ND \\
\hline MECA-325 & - & - & - & ND \\
\hline \multicolumn{5}{|l|}{ Histochemistry } \\
\hline Acid phosphatase & + & + & - & - \\
\hline Alk. phosphatase & - & - & - & Rare + \\
\hline $\begin{array}{l}\text { Chloroacetate } \\
\text { esterase }\end{array}$ & - & - & - & - \\
\hline $\begin{array}{l}\text { Nonspecific- } \\
\text { esterase }\end{array}$ & + & + & Weak + & ND \\
\hline Sudan black B & - & - & - & + \\
\hline
\end{tabular}

(Fat cells)

+ , present; - , absent; ND, not done; Alk., alkaline.

* The LTBC were derived from the four radiation chimeras and the two fetal chimeras which had been engrafted for $>1 \mathrm{yr}$. At least one adherent layer from each of these chimeras was studied for the expression of markers that proved to be specific for donor or host cells. ₹ Occasional Factor VIII-positive cells morphologically consistent with megakaryocytes were seen in very young cultures.

${ }^{\S}$ Because all of the host-derived cells, except for occasional fat cells, proved to be collagen IV positive in completely reconstituted chimeras, in these studies the donor-derived cells were identified by the absence of collagen IV.

could not be distinguished by the pattern or intensity of staining that was done with the lineage-specific antibodies (Table III).

The host-derived adherent cells in LTBC are predominantly endothelial-like cells that synthesize collagen IV and laminin. To characterize the lineage of the host-derived cells, the adherent cells of LTBC were first stained for the host-specific surface antigen and subsequently stained for a variety of lineage-specific cytoplasmic antigens as described in Methods. With the exception of occasional fat-containing cells (discussed below), all of the host-derived cells stained positively with an antiserum specific for collagen type IV. In control experiments performed to confirm the specificity of the anticollagen IV antiserum, preincubation of the antiserum with purified collagen IV blocked the staining of adherent cells whereas preincubation with collagen I did not.

Fig. 1 shows the characteristic morphology and collagen IV staining of this host-derived cell population. These cells were generally larger than the donor-derived cells, sometimes cover- ing an area greater than one high-power field (630X), and had large nuclei, easily identifiable nucleoli, and abundant cytoplasm. Both elongated and sheet-like forms were present, and the cells tended to grow in clusters, usually closely associated with one or more phagocytic cells. Surface staining for $H-2 K^{b}$ was brighter on the smaller endothelial-like cells and was enhanced by the addition of $\alpha \beta$-interferon to the culture medium.

The cells that expressed collagen IV were also positive for laminin, and at 2-3 wk, for fibronectin (4) (Table III). Simultaneous two-color immunofluorescence for collagen IV and laminin demonstrated a complete concordance of staining for these two antigens in several hundred individual cells that were examined. In addition, these cells uniformly expressed the antigen detected by the MAb MECA-10, which stains endothelial cells in mouse thymus and spleen, as well as gut-associated connective tissue elements (Butcher, E. C., personal communication). MECA-325, which is specific for high-endothelial venule cells (21), was negative on the adherent cells of LTBC.

Collagen IV-positive cells of donor origin were not identified in any chimera examined, including the two fetal chimeras studied early after transplantation (2-4 mo) and the six chimeras examined late after transplantation (10 mo-2 yr), despite typing of several hundred cells in each case. In addition, these cells were consistently negative for Factor VIII, collagens I and III, and the hematopoietic-specific antigens Mac-1, F4/80, and T200 (Table III).

Host-derived adherent cells of LTBC also include fat cells. Although the great majority of the host-derived cells were positive for collagen IV and laminin, a minor population of cells which resembled adipocytes were negative for these markers (Fig. 2). Surface staining for the host strain-specific $H-2 K^{b}$ antigen demonstrated that these easily recognized cells were exclusively host in origin. Reexamination of the same microscopic fields after staining with Sudan black B confirmed the presence of fat within these cells.

\section{Discussion}

To determine the lineage, origin, and transplantability of the adherent cell types in LTBC we have analyzed cultures derived from two distinct chimeric mouse models, traditional radiation chimeras and $W^{x} / W^{v}$ fetal chimeras. In this latter model, the introduction of normal bone marrow cells early in fetal development carries several advantages for these studies. For example, because the fetal recipients are immunologically immature, they will accept engraftment of allogeneic cells carrying multiple strain-specific markers, including the major histocompatibility antigens, without the problem of rejection $(10,11)$.

More importantly, in the $W^{x} / W^{v}$ fetal hosts, the introduction of donor cells before bone marrow development and without radiation conditioning essentially precludes the engraftment of nonhematopoietic cells (12). Thus, the donor origin of a specific cell type in the fetal chimeras constitutes strong evidence for their derivation from hematopoietic stem cells. By comparing these fetal chimeras with traditional radiation chimeras, we have been able to determine both the origin and transplantability of the cells that constitute the in vitro hematopoietic microenvironment. 

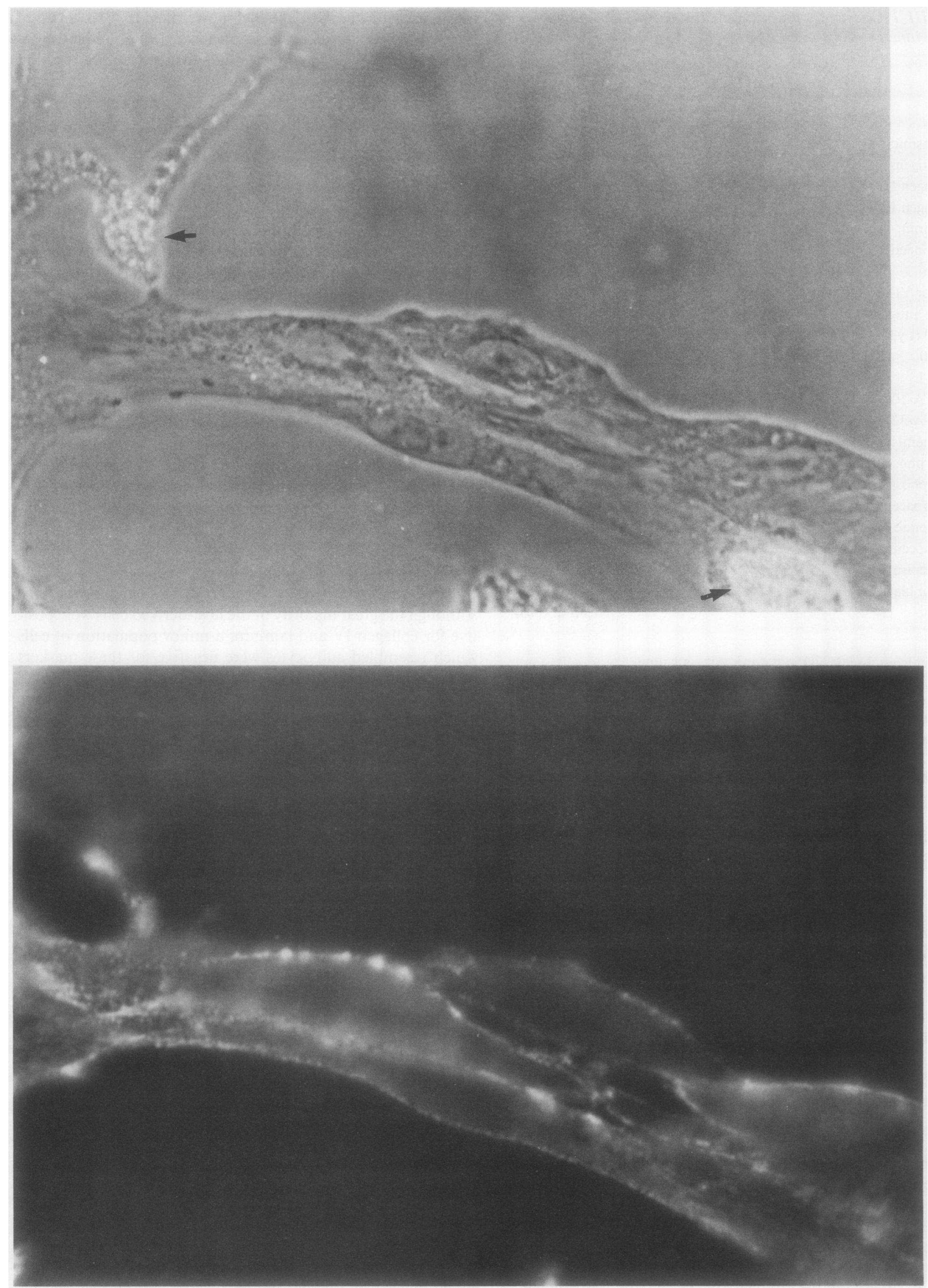


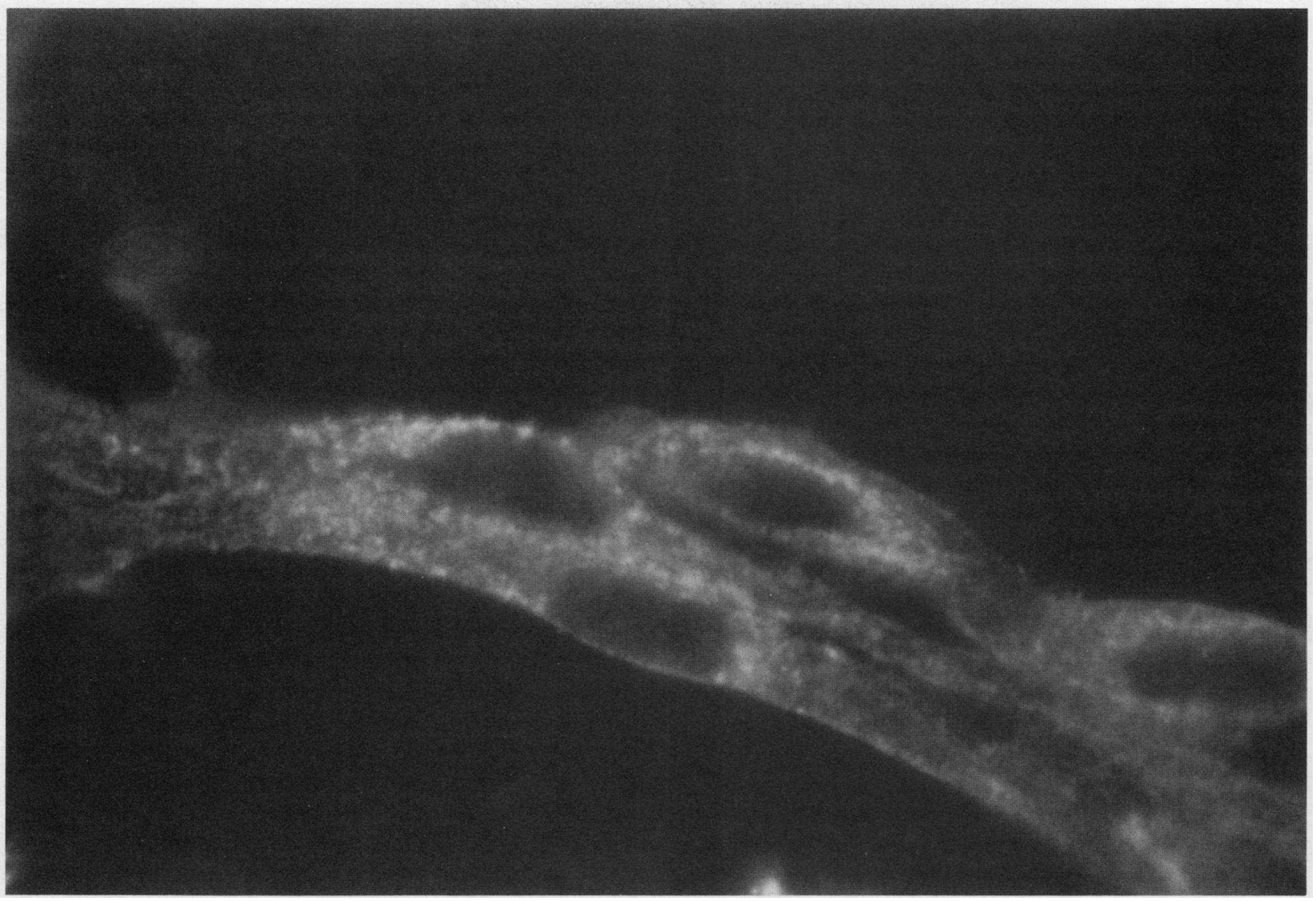

Figure 1. Double label immunofluorescence staining of endotheliallike cells. After incubation with latex particles and staining for the host-specific surface antigen and cytoplasmic collagen IV, the adherent layer cells from a chimeric mouse were photographed sequentially under phase contrast (top), green fluorescence for the host-specific antigen (middle), and red fluorescence for collagen IV (bottom).

The results of this in situ immunofluorescence analysis demonstrated that $\sim 90 \%$ of the adherent cells in LTBC, from both radiation and completely reconstituted $W^{x} / W^{v}$ chimeras, were donor derived, and thus are predominantly transplantable cells of hematopoietic origin. Independent GPI electrophoretic analyses of whole adherent layers from these chimeras also showed that $70-95 \%$ of the adherent cells are donor in origin, which agrees with previous studies that used strain-specific enzyme markers in antibody-facilitated and radiation chimeras $(7,23,24)$.

The hematopoietic origin of the donor-derived cells was further confirmed by studies demonstrating the monocytemacrophage cell lineage of this population. Specifically, the donor-derived cells stained uniformly with the macrophagespecific MAb, F4/80, as well as with anti-Mac-1 and antiT200. Moreover, up to $95 \%$ of these cells were phagocytic. The reason for the lack of phagocytosis in a small fraction of the donor-derived cells is unclear; however, they may represent macrophage progenitors or macrophages that have lost their ability to phagocytose. The demonstration of these nonphagocytic hematopoietic cells in LTBC, however, may require a reinterpretation of studies in which phagocytosis served as the only marker for the presence or absence of hematopoietic cells in marrow cultures (6).
The positive surface staining observed in the middle panel, and cytoplasmic staining observed in the bottom panel, demonstrate the host origin and expression of collagen IV, respectively, in these cells. Phagocytic cells of donor origin (arrows), which are negative for the host-specific surface antigen and for collagen IV, are also visible in this microscopic field. $(\times 630)$.

While the adherent cells of LTBC are predominantly donor-derived hematopoietic cells of the monocyte-macrophage lineage, both the immunofluorescence and enzyme analyses demonstrated that host-derived cells represented $5-25 \%$ of all the adherent cells. Moreover, apart from a minor population of fat cells, all of the host-derived cells labeled strongly with antibodies to collagen IV and laminin, which are cell products associated with endothelial cells. The cells expressing collagen IV also stained uniformly with the MECA-10 $\mathrm{MAb}$, which stains endothelial cells in murine hematopoietic organs. The significance of this finding must be interpreted with caution, however, as this antibody appears to have significant cross-reactivity with connective tissue elements, especially of the gut (Butcher, E. C., personal communication). Other investigators, using collagen IV and Factor VIII antigen as markers, have estimated that endothelial cells make up $5-25 \%$ of the adherent cells of murine and human LTBC (4, 5). In our hands, however, Factor VIII antigen staining has been consistently negative. Conceivably, Factor VIII antigen may be lost in cell culture, as has been described for the endothelial cells from one species (25).

The only other clearly recognizable stromal cells were adipocytes, which usually constituted $<1 \%$ of the adherent cells in subconfluent cultures, and increased in number as cultures 

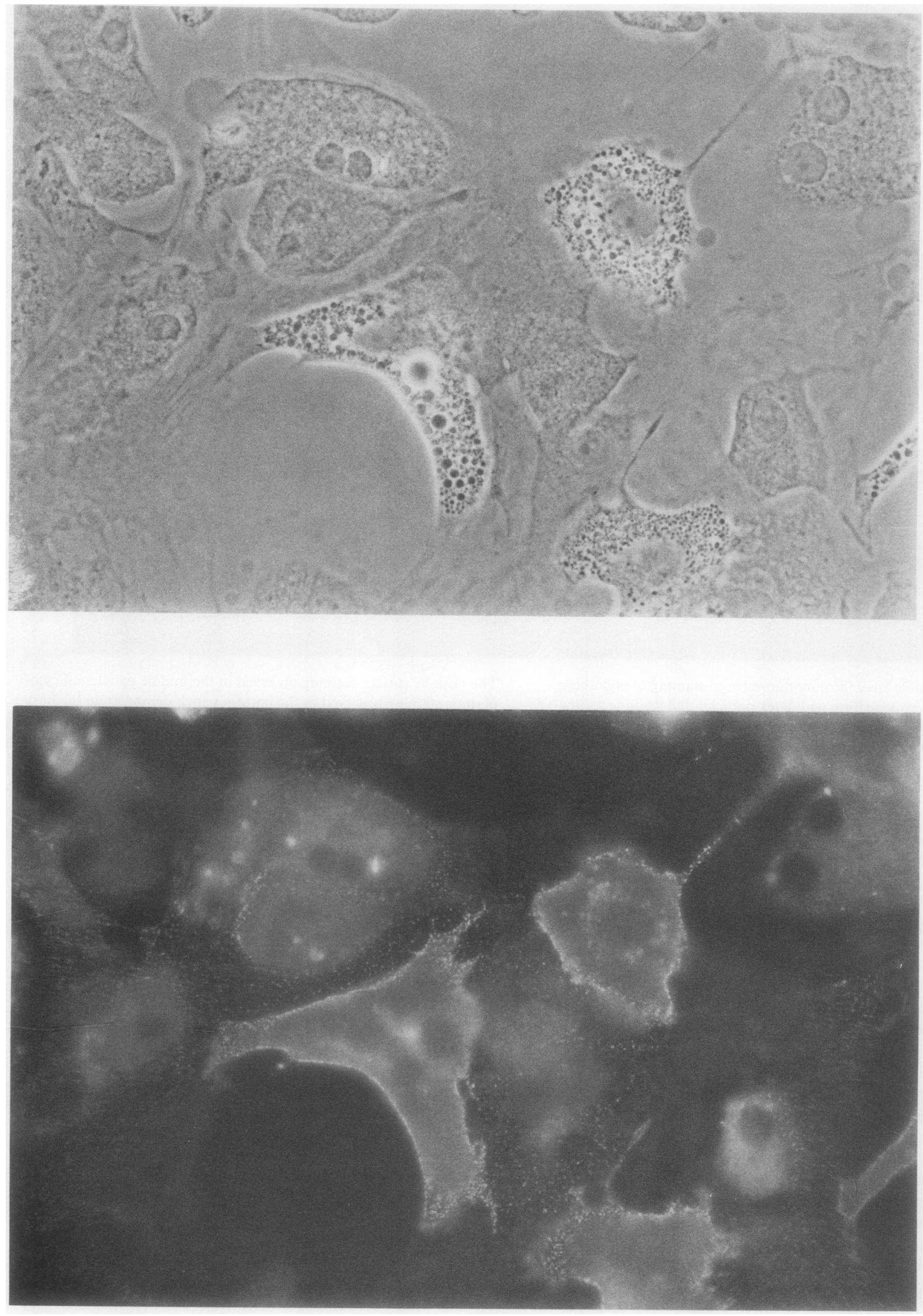


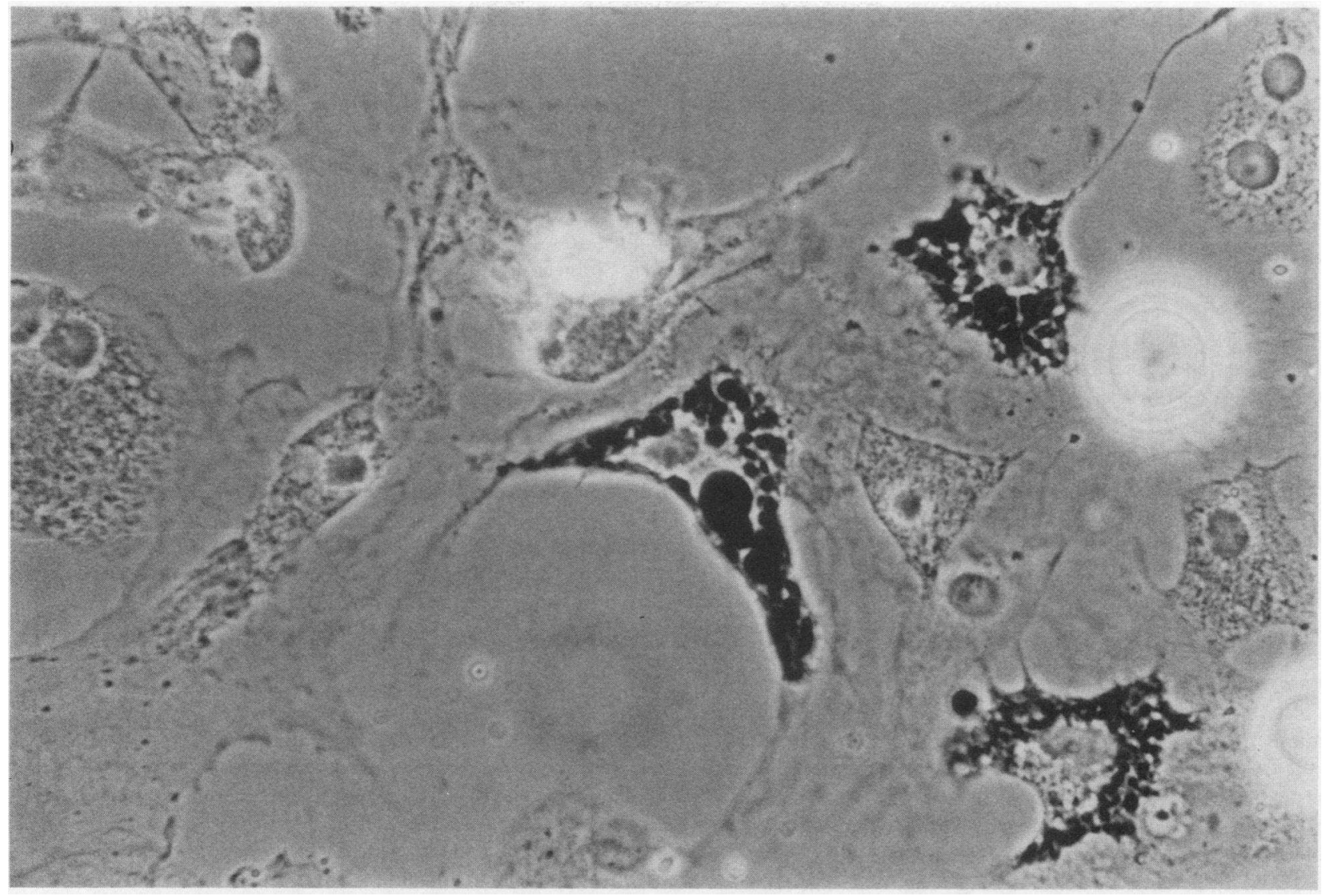

Figure 2. Immunofluorescence and Sudan black B staining of fat cells. The adherent layer from a chimeric mouse was stained for the host-specific surface antigen, and cells with the morphologic appearance of adipocytes were photographed sequentially under phase contrast (top) and fluorescence conditions (middle). The positive surface fluorescence evident in the middle panel demonstrates the host ori- gin of these cells. As described in Methods, the adherent cells were then stained for Sudan black B, and the microscopic field was relocated and photographed under phase contrast (bottom). The positive Sudan black $b$ staining observed in the bottom panel confirms the presence of fat in these cells. $(\times 630)$. aged and hematopoiesis declined. These cells were also exclusively host in origin and may derive from adventitial reticular cells (26). Indeed, alkaline phosphatase positive cells were detected in the chimeric LTBC at a frequency similar to that of the fat cells. Although collagen I was detected extracellularly in our cultures, we were unable to identify adherent cells that were positive for cytoplasmic collagens I and III, a finding consistent with some, but not all, other reports $(3,4,27-29)$.

Thus, contrary to the results of human studies, our experiments demonstrate that the endothelial-like cells and fat cells in murine LTBC are not transplantable and are not derived from hematopoietic stem cells. Conceivably, limitations in the methods used in the human studies may account for the earlier findings. For example, as many as half of all the stromal cells in male, control adherent layers could not be scored by the Y-body analysis used in the investigation of transplant patients (5). Similarly, in the studies of patients with myeloproliferative disorders (9), control experiments showed that the glucose-6phosphate dehydrogenase enzyme marker would not detect $<5-10 \%$ nonclonal fibroblasts in an otherwise clonal adherent layer. Thus, both of these methods are limited in their ability to detect minor cell populations.

In contrast, the present approach represents a highly sensitive and specific technique for the in situ identification of virtually every cell in an adherent layer. We conclude from this study that the adherent cells of LTBC are predominantly hematopoietic cells of the monocyte-macrophage lineage. A significant fraction of the in vitro stroma, however, is comprised of nonhematopoietic cells that express collagen IV and laminin. Since these endothelial-like cells accounted for virtually all of the host-derived stromal cells, they may represent an essential component of the in vitro hematopoietic microenvironment. The extension of these methods to the sorting of fresh marrow cells and established adherent layers will enable us to prepare relatively pure populations of the stromal cell types defined by these studies for analysis of their role in the maintenance and regulation of hematopoiesis $(24,30)$.

Since the submission of this manuscript for publication, it was reported that adherent cells expressing collagen and laminin in LTBC from human bone marrow transplant recipients are host in origin (31), a result in good agreement with the data reported here.

\section{Acknowledgments}

We thank Dr. R. G. Smith, Dr. E. P. Frenkel, and Dr. P. L. Witte for their helpful suggestions. 
This work was supported by the Nasher Family Cancer Research Program. S. Perkins is the recipient of a Clinical Fellowship from the American Cancer Society. R. A. Fleischman is the recipient of a John A. and George L. Hartford Fellowship.

\section{References}

1. Dexter, T. M., T. D. Allen, and L. G. Lajtha. 1977. Conditions controlling the proliferation of hemopoietic stem cells in vitro. J. Cell. Physiol. 91:335-344.

2. Dexter, T. M., and M. A. S. Moore. 1977. In vitro duplication and "cure" of haemopoietic defects in genetically anaemic mice. $\mathrm{Na}$ ture (Lond.). 269:412-414.

3. Bentley, S. A., and T. S. Tralka. 1982. Characterization of marrow-derived adherent cells: evidence against an endothelial sub-population. Scand. J. Haematol. 28:381-388.

4. Zuckerman, K. S., and M. S. Wicha. 1983. Extracellular matrix production by the adherent cells of long-term murine bone marrow cultures. Blood. 61:540-547.

5. Keating, A., J. W. Singer, P. D. Killen, G. E. Striker, A. C. Salo, J. Sanders, and E. D. Thomas. 1982. Donor origin of the in vitro haematopoietic microenvironment after marrow transplantation in man. Nature (Lond.). 298:280-283.

6. Piersma, A. H., R. E. Ploemacher, and K. G. M. Brockbank. 1983. Transplantation of bone marrow fibroblastoid stromal cells in mice via the transvenous route. Br. J. Haematol. 54:285-290.

7. Marshall, M. J., N. W. Nisbet, and S. Evans. 1984. Donor origin of the in vitro haemopoietic microenvironment after bone marrow transplantation in mice. Experientia (Basel). 40:385-386.

8. Bentley, S. A., T. Knutsen, and J. Whang-Peng. 1982. The origin of the hematopoietic microenvironment in continuous bone marrow culture. Exp. Hematol (NY) 10:367-372.

9. Singer, J. W., A. Keating, J. Cuttner, A. M. Gown, R. Jacobson, P. D. Killen, J. W. Moohr, V. Najfeld, J. Powell, J. Sanders, G. E. Striker, and P. J. Fialkow. 1984. Evidence for a stem cell common to hematopoiesis and its in vitro microenvironment: studies of patients with clonal hematopoietic neoplasia. Leuk. Res. 8:535-545.

10. Fleischman, R. A., and B. Mintz. 1979. Prevention of genetic anemias in mice by microinjection of normal hematopoietic stem cells into the fetal placenta. Proc. Natl. Acad. Sci. USA. 76:5736-5740.

11. Fleischman, R. A., and B. Mintz. 1984. Development of adult bone marrow stem cells in H-2-compatible and -incompatible mouse fetuses. J. Exp. Med. 159:731-745.

12. Okamoto, T., K. Anthony, and B. Mintz. 1985. Abnormal development of genetically normal fetal hematopoietic stem cells in steel mutant mouse fetuses. Dev. Biol. 109:251-254.

13. Eldridge, P. W., and M. J. Dewey. 1986. Genotype-limited changes in platelet and erythroid kinetics in Friend-virus-infected allophenic mice. Exp. Hematol (NY). 14:380-385.

14. Metcalf, D. 1977. Hemopoietic colonies: in vitro cloning of normal and leukemic cells. Springer-Verlag, Berlin/Heidelberg/New York. 13-35.

15. Till, J. E., and E. A. McCulloch. 1961. A direct measurement of the radiation sensitivity of normal mouse bone marrow cells. Radiat. Res. 14:213-222.

16. Pober, J. S., M. A. Jimbrone, R. S. Cotran, C. S. Reiss, S. J. Burakoff, W. Fiers, and K. A. Ault. 1983. Ia expression by vascular endothelium is inducible by activated $\mathrm{T}$ cells and by human gamma interferon. J. Exp. Med. 157:1339-1353.

17. Ledbetter, J. A., and L. A. Herzenberg. 1979. Xenogeneic monoclonal antibodies to mouse lymphoid differentiation antigens. Immunol. Rev. 47:63-90.

18. Springer, T., G. Galfre, D. S. Secher, and C. Milstein. 1979. Mac-1: a macrophage differentiation antigen identified by monoclonal antibody. Eur. J. Immunol. 9:301-306.

19. Austyn, J. M., and S. Gordon. 1981. F4/80, a monoclonal antibody directed specifically against the mouse macrophage. Eur. $J$. Immunol. 11:805-815.

20. Stanley, J. R., O. M. Alvarez, W. Bere, W. H. Eaglestein, and S. I. Katz. 1981. Detection of basement membrane zone antigens during epidermal wound healing in pigs. J. Invest. Dermatol. 77:240243.

21. Duijvenstijn, A. M., A. B. Schreiber, and E. C. Butcher. 1986. Interferon-gamma regulates an antigen specific for endothelial cells involved in lymphocyte traffic. Proc. Natl. Acad. Sci. USA. 83:91149118.

22. Sheehan, H. L., and G. W. Storey. 1947. An improved method of staining leukocyte granules with Sudan black B. J. Pathol. Bacteriol. 59:336-337.

23. Francescutti, L. H., P. Gambel, and T. G. Wegmann. 1985. Characterization of hematopoietic stem cell chimerism in antibody-facilitated bone marrow chimeras. Transplantation (Baltimore). 40:7-11.

24. Lennon, J. E., and H. S. Micklem. 1986. Stromal cells in longterm murine bone marrow culture: FACS studies and origin of stromal cells in radiation chimeras. Exp. Hematol (NY). 14:287-292.

25. Pederson, D. C., and D. N. Fass. 1980. Failure to detect Von Willebrand factor in cultured porcine endothelial cells. Circulation. 62(Suppl. III):169. (Abstr.)

26. Weiss, L., and L.-T. Chen. 1975. The organization of hematopoietic cords and vascular sinuses in bone marrow. Blood Cells (Berl.). 1:617-633.

27. Castro-Malaspina, H., R. E. Gay, S. Saletan, B. Oettgen, and S. Gay. 1980. Phenotypic characterization of the adherent cell layer in long-term mouse bone marrow cultures. Blood. 58:107a. (Abstr.)

28. Bentley, S. A., O. Alabaster, and J. M. Foidart. 1981. Collagen heterogeneity in normal human bone marrow. Br. J. Haematol. 48:287-291.

29. Castro-Malaspina, H., S. Saletan, R. E. Gay, B. Oettgen, S. Gay, and M. A. S. Moore. 1980. Immunocytochemical identification of cells comprising the adherent layer of long-term human bone marrow cultures. Blood. 58:107a. (Abstr.)

30. Witte, P. L., M. Robinson, M. G. Low, D. L. Stiers, S. Perkins, R. A. Fleischman, and P. W. Kincade. 1987. Relationships between B-lineage lymphocytes and stromal cells in long term bone marrow cultures. Eur. J. Immunol. 17:1473-1484.

31. Simmons, P. J., D. Przepiorka, E. D. Thomas, and B. TorokStorb. 1987. Host origin of marrow stromal cells following allogeneic bone marrow transplantation. Nature (Lond.). 328:429-432. 